\title{
O ENSINO DA PSICOLOGIA SOCIAL: \\ A OPÇÃO PREFERENCIAL PELA CONCOMITÂNCIA TEORIA-PRÁTICA
}

(*) Almir Del Prette

\section{RESUMO}

Este texto apresenta uma proposta de concomitância teoria-prática para o ensino da Psicologia Social e analisa as decisões de um professor relativas à sua implementação, descrevendo-se resumidamente os objetivos, conteúdos e procedimentos da disciplina. A proposta baseia-se em reflexōes sobre conceito de aprendizagem na disciplina, sobre a necessidade de selecionar um referencial teórico, dada a multiplicidade de enfoques na Psicologia Social e, principalmente, sobre o conceito de prática e a natureza de sua articulação com a teoria enquanto guia para a seleção dos procedimentos.

\section{INTRODUÇÃO}

A experiência a ser relatada refere-se a uma tentativa de introduzir, no ensino da disciplina Psicologia Social, a análise do fato social. Não é do escopo desta reflexão apresentar resultados analíticos quantitativos sobre o desempenho do aluno e do professor, mesmo porque não se organizou procedimentos sistemáticos que produzissem esses dados. Pretende-se, antes de tudo, analisar uma experiência e defender a idéia da relevância da aplicabilidade concomitante ou, o mais imediatamente possível, do arcabouço conceitual disponivel e pertinente aos programas curriculares. Além desses objetivos, pode-se acrescentar que o resenhamento da experiência didática favorece o intercâmbio, a crítica e, principalmente, a auto-avaliação.

A Psicologia Social representa, mais do que qualquer outra subdisciplina da Psicologia, uma conhecimento multifário. Como se isso não bastasse, ela se sobrepõe, em muitos pontos, a várias outras subdisciplinas e "invade", por assim dizer, as áreas das Sociais (Sociologia, Antropologia, Economia, etc.) às quais se acha intrinsecamente ligada. Em termos conceituais, a Psicologia Social compōe um amplo corpo de conhecimento, dispondo de algumas teorias mais abrangentes, que podem mesmo ser consideradas sistemas, e uma quantidade realmente incrivel de microteorias. Dessa forma, ao ministrar Psicologia Social, o professor se depara com um autêntico problem solving. Em outras palavras, vivencia um dilema na escolha, dada uma diversidade tão ampla, de alguns modelos ou teorias que podem

( ) Professor do Departamento de Psicologia e Educaçăo da F.F.C.L. de Ribeirăo Preto. 
ser trabalhados no período letivo disponível. Se se pensar no amplo espectro de problemas próprios de nossa sociedade, como por exemplo, racismo, violência, drogas, desemprego, trabalho, saúde, a questão da mulher, do menor, do idoso, etc., sobre os quais a Psicologia Social detém recursos explicativos, a dificuldade na tomada de decisão se acentua ainda mais.

Ao que tudo indica, as escolhas, em termos teóricos, oscilam entre as teorias cujo traço de modernidade é inquestionável e as consideradas clássicas. $\AA$ uma visão fragmentária-contextual do aparecimento da disciplina e de seu corpo teórico, freqüentemente se contrapōe uma perspectiva holista e historicista dos determinantes econômicos.

Mas, seja qual for o conjunto teórico definido nos programas e os princípios adotados, o aproveitamento do aluno é uma questão presente em todos os cursos.

A partir dos primeiros cursos de Psicologia Social que ministrei (*) percebi que a "aprendizagem conceitual" de muitos alunos não se mantinha ou não se generalizava para as situações acadêmicas subseqüentes. Dito de outra maneira, ao se engajar em um programa de pesquisa ou estágio, em contato com o fato social real, o aluno, via de regra, tendia a explicá-lo através de conhecimento vulgar ou, no máximo, combinava categorias analíticas inconciliáveis. Alguns chegavam a propor explicaçōes através de categorias políticas de cunho panfletarista, abstraindo os aspectos sobre os quais a disciplina que estudavam deveria oferecer respostas. Tal situação demandava novos esforços didáticos, já, então, mais difíceis de serem implementados.

Ao final dos cursos e das pesquisas, ficava-se com o sentimento incômodo de que não se alcançaram todos os objetivos didáticos propostos e que, malgrado os esforços do professor e dos alunos, as potencialidades não foram maximizadas.

Tais sentimentos levaram a repensar os cursos subseqüentes e, aos poucos, à descoberta de que somente a aplicação imediata dos esquemas conceituais na análise do fato social poderia se constituir da "contingência" ideal para as "aquisições cognitivas" do aluno. Isso implicou no abandono da noção de aprendizagem como aquisição de conteúdos de conhecimento e na adoção do conceito de habilidade. De fato, a habilidade de analisar implica na avaliação do valor heurístico do referencial teórico enquanto instrumento de compreensão da realidade e, ao mesmo tempo, na identificação de seus limites, lacunas, abrangência, pertinéncia, etc., quando contrastado com o fato social.

A idéia de prática, abordada acima, deve ser discutida buscando-se uma maior aprofundamento. Aparentemente, a prática na educação representa, em termos de principio, um pseudo-problema, na medida em que todos argumentam em seu favor. Estabelecer atividade prática parece, pois, se constituir de providencia axiomática, destituida, porisso, de maiores interesses. Nảo obstante,

(5) Psicologia SocialiV na UFPB entre 1987 a 1989 
algumas vezes, questionar o obvio é um exercício atil, que pode possibilitar uma nova visão sobre aspectos não facilmente identificados por permanecerem submergidos na providência consensual. Nesse sentido, vale perguntar o que $\boldsymbol{\epsilon}$ a prática. Se se aceita a noção corrente da definição por oposição, a prática é entendida como sendo o que se contrasta com a teoria. Aqui, simplesmente, temos dois pontos opostos igualmente nebulosos. Localizando a questão na Psicologia, parece haver um entendimento difuso de que quando o aluno, no cumprimento de uma tarefa especffica, interage com alguém da comunidade, ele está "praticando". Ora, na maioria das vezes, como por exemplo, na aplicação de um teste, o aluno está sob o controle direto de instruções e seu êxito depende de sua fidelidade ao que está ou foi prescrito. Outras questões podem trazer elementos importantes na qualificação da categoria prática, como por exemplo, a "prática" poderia ser exercida por alguém que não dispõe do conhecimento sobre os fundamentos lógico-conceituais da atividade em questão? A execução da tarefa produz alguma mudança naquele que a executa (aluno) e no objeto da intervenção (sujeito)? A resposta a essas questōes mostra que a prática ultrapassa o mero "fazer" e deve ser vista, portanto, no âmbito da educação, como uma atividade transformativa que deveria propiciar ao educando, a sua própria elaboração de conhecimento (algumas vezes mesmo se contrapondo ao obtido nos bancos escolares) e ao sujeito, que se torna objeto da intervenção, o partilhamento do problema e do crescimento na direção de sua solução. Assim considerada, prática não se opõe à teoria, mas se relaciona com ela de forma interdependente e dialética.

Essas considerações serviram de base para o curso de Psicologia Social IV na UFPB, em 1989, e orientaram as alterações propostas para o programa de Psicologia Social II, na F.F.C.L. da USP de Ribeirão Preto em 1990.

\section{A estrutura do curso}

O curso de Psicologia Social II se insere na grade curricular no curso de graduação em Psicologia na F.F.C.L. (USP - Ribeirão Preto) como optativo, sendo oferecido no sexto semestre letivo, com uma carga horária de 90 horas. $O$ conteúdo programático, distribuído em três unidades, e seus objetivos, estavam organizados e definidos, quando o curso passou para a nossa responsabilidade no segundo semestre letivo de 1990. Do referido conteúdo optou-se (em discussão com os alunos) por alterar a terceira unidade e incluir, como objetivo geral, a capacitação do aluno na análise do fato social. O conteúdo programático, em sua nova versão, ficou disposto em três unidades: redefinição da Psicologia Social, principais categorias de análise e ação coletiva e movimentos sociais.

\section{Procedimentos de sala de aula}

Além dos procedimentos usualmente adotados, tais como, a) apresen- 
tação e discussão do curso (objetos, conteúdos e bibliografias); b) verificação e discussāo de leituras semanais; c) exposição de conteudos e temas; d) acompanhamento, avaliação e feedback, buscou-se outros, que atendessem ao objetivo geral proposto.

Considerando-se a tentativa de capacitação do aluno nas habilidades de análise do fato social, dispensou-se os procedimentos tradicionais de verificação de aprendizagem do tipo "devolução e/ou aplicação de conceitos" a partir de questōes dadas. Manteve-se, porém, as orientaçōes e discussōes em pequenos grupos para, em seguida, colocar o aluno diante de um fato social com a incumbência de analisá-lo.

$\mathrm{Na}$ tarefa de análise, os fato sociais foram selecionados considerando-se seu nivel de complexidade crescente. $O$ produto final (análise) se constituía de um relatório contendo, sempre que possível, um resumo do fato com base na fonte, a análise desse fato com a utilização do referencial teórico disponível e uma avaliação da experiência. Durante o período de trabalho do aluno, principalmente nas primeiras tentativas, introduzia-se ou retirava-se suportes (instruçōes, dicas, exemplos e modelos), objetivando diminuir as tentativas malsucedidas e possibilitar um produto final mais gratificante. Esse procedimento de ajuda variava em dependência da complexidade da tarefa e do desempenho do aluno ou do grupo.

Os fatos sociais selecionados para a análise foram: relato resumido de um conflito social contendo justificativas dos participantes (recorte de jornal); descrição das atividades de um operário (Schmidt), da negociação entre este e seu gerente sobre a maximização de seu desempenho e salário e da avaliação feita pelo gerente sobre a "psicologia" do operário (excertos do The Principles of Scientific Management de Taylor, in Harry Braverman); relato de uma situação de conflito entre membros de um júri popular com a tarefa de julgar um acusado de assassinato onde um dos jurados diverge da maioria e procura convencer os demais da inocência do réu (filme "12 homens e uma sentença" de Sidney Lumet) e a narrativa da história de dois jovens que se envolvem emocionalmente durante a segunda guerra mundial, produzindo preconceitos e relações intergrupais conflitantes na comunidade (filme "Um amor na Alemanha" de Andrye Wajda).

As categorias de análise sobre o trabalho e produção (Marx e Engels), as teorias sobre influência social e minorias ativas (Asch, Moscovici e Mugny) e sobre a emergência de grupos, estereótipos, comportamento intergrupal e identidade social (Sherif e Sherif, Doise, Tajfel e Turner), serviram como referencial conceitual para as tarefas de análise.

\section{A guisa de conclusháo}

Os relatórios dos alunos evidenciam um certo rigor da postura científica na análise do fato social. As incursões gratuitas no jargão político-panfletário das 
"contradições sociais" e do "poder que al está" não apareceram na análise. Ao invés disso, observou-se o esforço na direção do uso de categorias analíticas do referencial teórico dado. É certo que nem sempre houve coerência e parcimônia no uso dos conceitos mas, considerando-se o tempo disponível e a ausência de treino prévio, pode-se dizer que o avanço foi significativo.

Alguns problemas devem ser considerados. Um deles refere-se à dificuldade de redigir que, em geral, o aluno apresenta. A redação parece pois se constituir em requisito necessário para a análise. Além dessa dificuldade, observou-se, inicialmente, um certo cepticismo em relação à propriedade da habilidade de análise para o bom exercício da profissão. A leitura do livro "Os cientistas precisam escrever" (Barrass, 1986) e relatos anedóticos enfatizando a importância da análise parecem ter alterado essa postura que, sem dúvida, se relaciona com a própria dificuldade de encarar as falhas e erros na produção escrita. Dois limites principais podem ser relatados no curso. Um refere-se à impossibilidade de colocar o aluno diante do fato social concreto e o outro localiza-se na restrição à possibilidade de diversificar os fatos sociais apresentados aos alunos.

Um aspecto bastante relevante a ser considerado refere-se à motivação. Considerando a natureza da tarefa, poder-se-ia pensar que os alunos se desinteressariam pelo curso e solicitariam o retorno aos procedimentos habituais. Ao invés disso, observou-se que os mesmos se esforçaram na execução das tarefas. A freqüência (não controlada) em sala de aula e a avaliação da experiência permitem inferir que, de maneira geral, o nível motivacional foi mais do que razoável. Alguns excertos das avaliações evidenciam a motivação dos alunos.

"... foi interessante poder verificar na prática as correlações feitas por Moscovici entre maioria $e$ minoria".

"A teoria de Tajfel proporcionou entender o filme através da análise psicossociológica, em que entende-se o comportamento dentro de um contexto mais amplo".

"O estilo de avaliação proposto é interessante no sentido que foge ds formas tradicionais (...) isto força as pessoas a lerem $e$ a relerem os textos e estarem confiantes $e$ seguras sobre a própria aprendizagem".

"Sinto que, embora trabalhoso e todas as dificuldades, dadas as condiçoes do semestre, que interferem nesse tipo de experiência, ela é necessária para a nossa formaçdo". 
"A aplicação da teoria ao meu ver é uma das coisas que mais motivam a releitura de um texto".

Finalmente, deve-se considerar que a identificação da "permanência" e da "generalização" das possíveis habilidades desenvolvidas no curso é questão empírica. Não obstante, a observação não sistemática e a reflexão sobre as diversas experiências de ensino permitem realçar a superioridade da prática concomitante e, portanto, justificar a sua opção preferencial no ensino da Psicologia Social.

\section{Bibliografia utilizada no curso.}

Considerando-se a inexistência de livros com características de compêndios que pudessem abranger os fatos sociais para a análise, optou-se por uma maior diversidade de textos. O referencial utilizado segue abaixo, anotando-se, ao final de cada indicação o capítulo ou parte utilizado.

ASCH, S. Psicologia Social. São Paulo, Cia Editora Nacional, 1972 (parte V,16)

BARRASS, R. Os cientistas precisam escrever. São Paulo, T. A. Queiroz Editor, 1986 (cap. 4).

BRAVERMAM, H. Trabalho e capital monopolista. Rio de Janeiro, Zahar Editores, 1981 (pags. 95, 96, 97 - $3^{\mathrm{a}} \mathrm{ed}$.)

CARDOSO, R. A aventura antropologica. Rio de Janeiro, Paz e Terra, 1986 (parte 2)

CHAUI, M. O que é ideologia? São Paulo, Brasiliense, 1984.

DEL PRETTE, A. Pesquisa em movimentos sociais: reflexões sobre uma experiência. Psicologia e Sociedade, 1988/89, 3:101-107.

DEL PRETTE, A. teoria das minorias ativas: pressupostos, conceitos e pesquisa. (mimeo, 1990).

DEL PRETTE, A. Em busca de uma abordagem psicológica no estudo dos movimentos sociais. Ciência e Cultura. (no prelo).

DOISE, W. A articulação psicológica e as relações entre grupos. Lisboa, Moraes Editores, 1985. (cap. 3).

HUBSCH, H. e Vorwerg, M. Introdução à Psicologia Social Marxista. Venda Nova-Amadora, Novo Curso Editores, 1980. (cap. 1). 
LANE. S. T. M. e Codo, W. (orgs.) Psicologia Social - o homem em movimento. São Paulo, Brasiliense, 1985. (parte 1).

LÖWY, M. Ideologias e ciências sociais. São Paulo, Cortez, 1985.

MARX, K. O capital. Rio de Janeiro, Editora da Civilização Brasileira. (Livro 1, cap. XIV).

TAJFEL, H. Mudança Social e psicologia Social. Lisboa, Livros Horizonte, 1981 (comportamento inter grupo e Psicologia Social da mudança).

\section{ABSTRACT}

This paper presents a proposition of theory-practice concomitance to the Social Psychology teaching. It analyses the teacher's decisions concerning its implementation, describes the goals, contents and procedures of the subject. The proposition founds on considerations about the concept of learning in the subject, about the need to select a theoretical perspective among those of Social Psychology, and mainly about the concept of practice and the nature of its connection with theory, as a guide to select procedures. 
$-60$ 